\title{
Ecological and historical factors in fern biogeography
}

\author{
David S. Barrington Pringle Herbarium, Department of Botany, University of Vermont, Burlington, VT \\ 05405-0086 U.S.A.
}

\begin{abstract}
Remarkable diversity in recognized endemic centres as well as noteworthy disjunct distributions have led students of the pteridophytes to seek historical explanations for these phenomena. A suite of distinctive attributes limit the array of possible explanations: most biogeographically significant are (1) the smaller number of species-range determinants, and (2) the substantial capacity for long-distance dispersal. These attributes constrain the train of events triggered by global events and culminating in the particular phylogenetic history of an evolutionary lineage. Fern biogeographers most often infer historical changes in habitat distribution predicated by climatic change from distribution
\end{abstract}

patterns of phylogenetic lineages. Long-distance dispersal and vicariance are both prominent explanations for present-day disjunct distributions. Endemic centres develop in tropical wet-montane regions because of long-distance dispersal of species into the centres and retention of species in these ecologically diverse centres. Geographical rather than ecological isolation probably provides the isolation for evolutionary divergence in these species-rich regions.

Key words. Biogeography, ferns, isolating mechanisms, longdistance dispersal, vicariance.

\section{INTRODUCTION}

The progress of science is sometimes enhanced by reference to evolutionary groups that differ in life-history attributes from commonly studied lineages. The ferns are such a lineage; neither as dispersible as fungi nor as sedentary as ratite birds, they offer an independent test of how broadly biogeographic principles may be applied. They are most diverse in a small number of endemic centres that share climatic and topographic similarities (abundant rainfall and equable temperatures at higher altitudes: Christ, 1910), and they present a set of dramatic disjunctions (Wagner, 1972; Tryon, 1986). The regions of high diversity and the disjunct distribution, invite historical and ecological explanations. Long-distance dispersal is important (A. Tryon, 1965; R. Tryon, 1970), but abundant evidence for vicariance in their history now exists (e.g. Hill, 1986; Kato, 1993). In this paper I explore the causal nature of fern biogeography, having outlined the biogeographically distinctive attributes of these organisms. These considerations in place, two key features of fern biogeography are addressed, disjunct distributions and endemic centres. Finally it is suggested that geographic rather than ecological isolation provides the basis for species diversity in endemic centres.

\section{BIOLOGICAL CONSTRAINTS ON BIOGEOGRAPHIC INFERENCE AMONG THE FERNS}

What are the biogeographically distinctive attributes of the ferns, relative to the more commonly studied angiosperms and higher vertebrates? Three factors relevant to biogeography are most prominent. First, since the ferns are independent of pollen and seed vectors and have very few co-evolved herbivores, habitat preference-and hence distribution - reflect climate and other abiotic features such as substrate rather than an intricate combination of climatic and co-evolutionary features. As a result, fern biogeographers have a simpler set of factors to consider in inferring the ecological determinants of geographic distribution. This more direct relationship between climate and distribution makes ferns especially useful biogeographic tools. This relationship is often narrowly circumscribed, as both Given (1993) and Kornaś (1993) have documented.

Secondly, the unique reproductive biology of ferns appears at first to impose some constraints on the ecology and distribution of fern species. Gametophyte sexuality, leptokurtic spore dispersal pattern (Conant, 1978) and limited sperm range suggest that intergametophytic (and sometimes intragametophytic) selfing (terminology from Klekowski, 1969) are the rule. As a consequence, considerable local differentiation and low heterozygosity would be expected. However, for many species surveyed (Soltis \& Soltis, 1990) most isozyme electromorphs are found in most populations; regular long-distance dispersal seems to compensate for presumed localizing effects. This genetic homogeneity may be a consequence of spore rains from various surrounding populations reaching the open terrain typically colonized by fern gametophytes.

Thirdly, long-distance dispersal is a dominant force in 
fern distribution. Long-distance dispersal of ferns is effective, since many ferns have small, lightweight spores with the potential to develop into a gametophyte capable of producing both egg and sperm. The high proportion of fern species in the floras of remote oceanic attests to their capacity for long-distance dispersal (Tryon, 1970). The ecological differentiation of the life cycle into physically separate colonizer gametophyte and persistent sporophyte phases enhances capacity for long-distance dispersal. The benefit is the flexibility to begin as a colonist and proceed to take a place in an intact flora. A gametophyte developing from a newly arrived spore colonizes highly disturbed terrain in marginal situations, but established sporophyte plants find places in intact ecosystems, where they are often good competitors.

\section{CAUSE AND EFFECT IN FERN BIOGEOGRAPHY}

Fern distributions are explained in the context of a train of events triggered by global (geophysical) changes such as tectonic events and culminating in the particular phylogenetic history of a lineage. Typically, tectonic events bring about changes in climate, which alter the local habitat in which ferns live. Ferns, like most living things, respond to these habitat changes in three ways: migration to more suitable terrain, adaption to the new conditions, and extinction. Migration may be incremental, that is simple shifting of the distribution across the globe with climate and habitat. However, change in distribution can yield range disjunctions via long-distance dispersal or vicariance. These discontinuous population systems have acquired the isolation prerequisite but not causal to species divergence. Phylogenetic divergence is the ultimate outcome of the set of events initiated by global change. Typically, fern biogeographers consider distributions in the light of geological, ecological and evolutionary evidence with the goal of understanding the role of biogeography in the history of lineages.

\section{THE STRUCTURE OF BIOGEOGRAPHIC ARGUMENTS FOR FERNS}

The most basic arguments in fern biogeography address the role of long-distance dispersal and vicariance in the origin of disjunctions. More complex are the arguments for the origin of diverse floras in endemic centres. The divergence process in these endemic centres as well as the arrival of species from afar are both important. Often, developing a biogeographic explanation for the distribution of a fern lineage requires a complex set of inferences about both disjunctions and divergence events dependent on its particular habitat preference and reproductive biology. Fossil data often dramatically strengthen the argument (Dettman, 1990).

\section{Changes in distribution}

\section{Origin of disjunctions: Iong-distance dispersal}

Because of the prominent role of long-distance dispersal in the biogeography of ferns, it is important to distinguish between long-distance dispersal and vicariance in the origin of disjunct distributions. Given the high dispersibility of fern spores, vicariance might seem to play only a minor role in 'the history of fern distribution. However, both long-distance dispersal and vicariance are important explanations for fern distributions.

Long-distance dispersal is simplest to argue, since the list of assumptions is shortest. For oceanic islands, these arguments are compelling because the islands have always been oceanic and hence the insular population has neither been rifted nor isolated by reduction of a previously continuous distribution. The Hawaiian Islands, as they are part of a geologically well-documented archipelago of islands being generated at the same remote place in the Pacific for at least the past 67 million years (Rotondo et al., 1981), provide a powerful example.

Deciding the direction of long-distance dispersal, a problem much harder to address on continents, turns out to be easier for long-distance dispersal of ferns to oceanic islands. Tryon (1970) notes that species with large continental populations contribute the most species to oceanic islands. In general it is the large population that produces enough propagules to make crossing the oceanic barrier probable; the small insular population is almost certainly derived. Thus defensible historical explanations for present distribution patterns are possible for long-distance dispersal to oceanic islands.

Are continental situations similar? They are, given evidence for the long-term small size and rarity of a specific habitat type. Easiest to defend are extreme disjunctions of montane species. For instance, Polystichum orbiculatum (Desv.) Rémy is an Andean páramo species with a presentday altitudinal range of (2700-)3200-4000 m (Tryon \& Stolze, 1991). Disjunct populations of the species are found in the Talamanca range of Costa Rica and Panama and the high mountains of Guatemala and Mexico, growing at altitudes of $3400 \mathrm{~m}$ and higher. The Central American and Mexican populations of $P$. orbiculatum probably arrived from the South via long-distance dispersal, since páramo environments have never descended low enough to allow incremental range change and subsequent vicariance involving the lowlands of the Darién and NicaraguaHonduras (Van der Hammen, 1981: data from the northern Andes). The direction of this dispersal is based on the likelihood that the Andes, with their larger area of appropriate habitat for this species, are the likely source.

\section{Origin of disjunctions: vicariance}

Vicariance is an important source of disjunct distributions in the ferns. Simple and compelling arguments for vicariance can be made. Camptosorus rhizophyllus (L.) Link and C. sibiricus Rupr. are a morphologically unique and evolutionary isolated species pair. Given the $16,000 \mathrm{~km}$ disjunction between the two species (eastern North America to eastern Asia), disruption of a formerly continuous range is the most probable explanation for the present distribution.

A stronger argument, including data on past distribution, is possible for Onoclea sensibilis L., a species disjunct 
between eastern Asia and Eastern North America and found nowhere else in the world. Its nearest ally, whether it be Onocleopsis hintonii F. Ballard or Onoclea orientalis (W. J. Hooker) W. J. Hooker (Kato, 1992), is morphologically remote. Again the great distance between the two extant populations suggests that they are not likely to have been established by long-distance dispersal.

Onoclea sensibilis has a long fossil record that includes all the major forested regions of the northern hemisphere. It is known from western Canada and Alaska in the late Cretaceous and Tertiary, from interior North America (Colorado and New Mexico) in the Cretaceous, from Eastern North America (including the Dakotas) from the Cretaceous forward, from northwest Europe in the Eocene and from Japan in the Eocene (Lloyd, 1971). Consequently vicariance seems more likely in light of the fossil record, which demonstrates an earlier broad distribution in northern forested regions. Though extinction of Onoclea populations with climatic change is the simplest explanation, episodes of long-distance dispersal in the history of this lineage are still possible.

In the absence of fossil evidence, arguments for vicariance can be based on other data, most commonly on reproductive biology. For instance, Paris (1991) has suggested a role for vicariance in the origin of the disjunct distribution of Adiantum aleuticum (Rupr.) Paris between Western North America and ultramafic substrates in northeastern North America. She has demonstrated that gametophytes of A. aleuticum are usually unisexual; at the same time, Peck et al. (1991) have shown that the closely allied $A$. pedatum L. carries high levels of genetic load, which severely restricts the intragametophytic selfing of gametophytes. Proceeding from this evidence, Paris argues that long-distance dispersal, presumably of single spores, is unlikely in the lineage because intergametophytic mating is probably the rule for the species complex. Instead, she postulates that incremental migration of the western Adiantum aleuticum along the highly disturbed terrain exposed with glacial retreat was followed by restriction to serpentine substrates in the east with post-glacial stabilization of eastern forests.

\section{Cibotium, a complex history}

In reality, long-distance dispersal, vicariance and incremental change in distribution must often be combined in explaining the history of individual lineages of ferns. The genus Cibotium, a dicksoniaceous tree fern, provides an excellent example combining several kinds of distributional change as well as speciation.

Cibotium is a Pacific-rim genus of about eight extant species, one in southeastern Mexico (C. schiedei Schlecht. \& Cham.), one or perhaps two ( $C$. barometz (L.) J. Sm. and C. cumingii Kze.) in the Old-World tropics from Assam and China to western Malaysia and the Philippines (Holttum, 1954; Copeland, 1958) and about six in the Hawaiian islands (Becker, 1984; Wagner, 1990). All grow at fairly low altitudes in high-rainfall tropical regions. Assuming that the genus is monophyletic, an argument for its biogeographic history must explain one of the most disparate disjunct distributions known in the ferns. Since the Hawaiian Islands are oceanic, and the species there are all more closely related to each other than to any other extant species, the strong inference may be made that they originated with one long-distance dispersal event from a continental source.

Interpreting the history of the two lineages on either side of the Pacific is more challenging, but the fossil record provides key insights. There are two fossils, both of stems, safely assignable to the genus Cibotium (Barrington, 1983; Ogura, 1933): C. oregonense Barr. is known from Eocene of Medford, $\left(c .42^{\circ} \mathrm{N}\right)$ Oregon, and C. iwatense Ogura is known from the Upper Cretaceous of Iwate, $\left(\right.$ c. $\left.39^{\circ} \mathrm{N}\right)$ Japan. This fossil record suggests that Cibotium was part of the boreotropical flora known to have been present in Europe, western North America and eastern Asia as far north as $50-65^{\circ} \mathrm{N}$ in the early Tertiary (Wolfe, 1975). The present-day species are the result of a southwardpresumably incremental - displacement, along with many of the other boreotropical elements; the Indomalay region home to present-day $C$. barometz is seen as a refugium for this flora (Wolfe, 1975). In this context, Hawaii could have received its migrant Cibotium at any time in the Tertiary. Since the Hawaiian species more nearly resemble the fossil and living New World taxa, a New World source for the Hawaiian lineage is postulated. (The New World source is shared with only $16.2 \%$ of the flora, considering the Hawaiian flora as a whole: Fosberg, 1951.)

\section{Hybridization and polyploidy in a biogeographic context}

The secondary contact of lineages as a result of historical processes is as likely as the sundering. In the ferns, this sets the stage for the formation of sterile hybrids and hybrid species (allopolyploids). The existence of a hybrid species implies the proximity of their progenitor species at some time in the past, since proximity to parents is typical of hybrids (e.g. R. Tryon, 1949). For instance, hybrids between species of Polystichum in Costa Rica are found in large mixed populations of their progenitors, with parental individuals within a few metres (Barrington, 1985).

Spatial proximity of hybrid progenitors does not however argue ecological similarity. There are numerous examples of hybrids arising from the interaction of ecologically disparate progenitors, an interaction possible so long as the habitats are adjacent. A well-known example from eastern North America is Dryopteris $\times$ boottii (Tuckerman) Underwood, the common hybrid between $D$. intermedia (Muhl.) Gray of northern deciduous forests and $D$. cristata (L.) Gray, confined to wooded wetlands. These species are ecologically but not geographically isolated; hybridisation between them is fairly frequent. Hybrids between ecologically disparate progenitors are most common in the most disturbed terrain, judging from the Costa Rican Polystichum hybrids. Ecological constraints apparently do not apply as rigidly in the highly disturbed sites, since species at their altitudinal limits are found in highly disturbed situations such as roadcuts, but not in original vegetation (Barrington, 1985). Perhaps these constraints are 
relaxed because of increased resource availability with the limited competition typical of open sites.

Hence, differences in habitat preference do not necessarily constitute isolating mechanisms, apparently because of effective spore dispersal and the generalized disturbancecolonizer adaption of the fern gametophyte. This suggests that true geographic allopatry rather than only ecological allopatry (allotopy) is a prerequisite for primary speciation in the ferns.

\section{Diversity in centres of endemism}

Tryon (1972) has documented centres rich in endemic species of ferns, which are divided from other such centres by regions of low endemism and species diversity (e.g. the Mexican and Costa Rican highlands, separated by the Honduras-Nicaragua lowlands). These endemic centres, which include such legendary species-rich regions as Mt. Kinabalu in Borneo and Assam as well as the tropical American centres addressed by Tryon, invite inquiry into their origins, since they potentially provide insight into the speciation process in ferns. They have in common a diverse, montane terrain with heavy rainfall in tropical regions. Three fundamental processes must build diversity in these regions: (1) successful arrival of propagules from remote sites, (2) differential survival of fern species in endemic centres, and (3) local diversification.

The Sphaeropteris horrida species group, revised by Tryon (1971), demonstrates the role of dispersal in the increase of diversity in endemic centres. Tryon demonstrates stepwise morphological changes in species of the group across the entire set of Latin American endemic centres from Mexico and the West Indies to Brazil. From these data he infers a history of incremental range change and long-distance dispersal through Latin America from North to South. As members of the lineage have migrated, geographic distance provided the isolation for speciation to ensue in each of the centres encountered. The Sphaeropteris horrida hypothesis serves as a model for the supply of new species to endemic centres via arrival of propagules from remote sites. In a historical context, Dettman (1990) argues on the basis of fossil-spore data that there have been species-rich endemic centres at various times in geologic history, which with global changes have served via dispersal as sources for the more modern endemic centres.

Long-distance dispersal is the most common source of new propagules arriving in endemic centres (Tryon, 1972). However, single propagules arriving via long-distance dispersal may actually retard the local differentiation typical of endemic centres. Since most spores completing long-distance dispersal will probably undergo intragametophytic mating, pioneer populations will tend to be genetically uniform (Buckley, 1990). Consequently, there is little variation from which to elicit differentiated evolutionary lineages.

Nevertheless speciation within endemic centres is well known. What are the typical patterns of differentiation within endemic centres? Two examples from the remote oceanic Hawaiian Islands set the framework for answering the question. The genus Sadleria is a monophyletic group endemic to the Hawaiian Islands (Lloyd, 1976). In Sadleria, ecological divergence has been part of the history of speciation in the islands. The sadlerias include both highly competitive species of wet forests and colonizing species of lava flows (Holbrook-Walker \& Lloyd, 1973). In contrast, the genus Diellia, also a monophyletic group endemic to Hawaii, comprises five species all of which occupy rocky gulches in the drier areas of forest and scrub on the lee sides of islands at low altitudes (Wagner, 1952). Similarly, Cibotium in the Hawaiian Islands has diversified without exploring a variety of ecological niches (Becker, 1984). Monophyletic groups on oceanic islands appear to include both ecologically isolated and geographically localized but ecologically uniform species sets.

In continental endemic centres, species complexes often include ecologically differentiated species. The evolutionary lineage including Cheilanthes squamosa Hooker \& Greville from the southern portion of the Andean endemic centre includes six species from various substrates, altitudes, and plant associations in different regions of the cordillera (Tryon, 1986; Tryon \& Stolze, 1989). Similarly, the fourteen species of Polystichum found only in the Mexican endemic centre show clear altitude and rainfall preferences and consequent distribution differences (Barrington, 1994). Thus, the characteristic variety of habitats in endemic centres provides a context for the diversity of species within an evolutionary lineage, and divergence within endemic centres must often include an exploration of the variety of habitats in the region. In the genus Pterozonium, nearly endemic to the Guayana Highlands of South America, species show differences in moisture and shade preference, substrate preference and altitudinal distribution. They also show marked regionalism including endemism to single tepuís (Lellinger, 1967). In this case, the small target size and isolation of the tepuí summits has probably promoted local endemism within the endemic centre.

In spite of the frequent ecological differentiation in endemic centres, ecological isolation is probably not important in fern speciation. Hybridisation studies in endemic centres, all of which are in the tropics, suggest that the biology and ecology of the hybridisation process in endemic centres are similar to the much better studied examples from North Temperate regions, at least at higher altitudes (Barrington, 1985, 1990). Ecological isolation does not seem central to speciation in endemic centres because inchoate species seem as likely as hybridising species to interbreed in spite of ecological divergence.

Geographic isolating mechanisms operating within endemic centres, especially in montane regions where small patches of suitable habitat may be isolated by the mountains themselves, may provide the actual isolation prerequisite to speciation - assuming the ecology of diverging populations is comparable to that of hybridizing species. Ferns occupying patchy habitats, such as Cheilanthes gracillima D.C. Eaton from semi-xeric rock outcrops, do show genetic divergence between populations (Soltis \& Soltis, 1990). It seems most likely that geographic isolation perhaps at local levels is critical to speciation in 
endemic centres, and that ecological differentiation is usually an ancillary process that accompanies or follows divergence rather than an isolating mechanism that allows evolutionary divergence to proceed.

\section{ACKNOWLEDGMENT}

I thank Cathy Paris for her several critical readings of this manuscript.

\section{REFERENCES}

Barrington, D.S. (1983) Cibotium oregonense: an Eocene tree-fern stem and petioles with internal structure. Am. J. Bot. 70, 11181124.

Barrington, D.S. (1985) Hybridisation in Costa Rican Polystichum. Proc. R. Soc. Edinb. 86B, 335-340.

Barrington, D.S. (1990) Hybridization and allopolyploidy in Central American Polystichum: cytological and isozyme documentation. Am. Mo. Bot. Gdn, 77, 297-305.

Barrington, D.S. (1994) Polystichum. Flora Mesoamericana V, 1 , Pteridophyta (ed. by R. C. Moran \& R. Riba N.) British Museum. London. (in press).

Becker, R. (1984) The identification of Hawaiian tree ferns of the genus Cibotium. Am. Fern J. 74, 97-100.

Buckley, D.M. (1990) Genetic and evolutionary implications of life cycle structure on the colonization ability and biogeography of pteridophytes. Abstracts, Progress in Pteridology Conference, 3-4. University of Michigan.

Christ, H. (1910) Die geographie der farne, Gustav Fischer, Jena.

Conant, D.S. (1978) A radioisotope technique to measure spore dispersal of the tree fern Cyathea arborez. Sm. Pollen \& Spores 20, 583-593.

Copeland, E.B. (1958) Fern flora of the Philippines, vol. I, Bureau of Printing, Manila.

Dettman, M.E. (1990) Mesozoic-Cenozoic history of several fern groups: evidence from the spore record. Abstracts, Progress in Pteridology Conference, 5-6. University of Michigan.

Fosberg, F.R. (1951) The American element in the Hawaiian flora. Pacific Sc. 5, 204-206.

Given, D.R. (1993) Changing aspects of endemism and endangerment in pteridophyta. J. Biogeogr. 19, 000-000.

Hill, C.R. (1986) Evolutionary cladistics of marattialean ferns. Bull. Brit. Mus. (Nat. Hist.) Bot. 14, 219-300.

Holbrook-Walker, S. \& Lloyd, R.M. (1973) Reproductive biology and gametophyte morphology of the Hawaiian fern genus Sadleria (Blechnaceae) relative to habitat diversity and propensity for colonization. J. Linn. Soc. 67, 157-174.

Holttum, R.E. (1954) Ferns of Malaya, Government Printing Office, Singapore.

Kato, M. (1992) Biogeography of ferns: dispersal and vicariance. J. Biogeogr. 19, 000-000.

Klekowski, E.J. Jr (1969) Reproductive biology of the pteridophyta, II. theoretical considerations. Bot. J. Linn. Soc. 62, 347-359.
Kornaś, J. (1993) The significance of historical factors and ecological preference to the distribution of African pteridophytes. $J$. Biogeogr. 19, 000-000.

Lellinger, D.B. (1967) Pterozonium (Filicales: Polypodiceae). The botany of the Guayana Highland-Part VII. (ed. by Bassett Maguire), Mem. New York Bot. Gdn, 17, 2-23.

Lloyd, R.M. (1971) Systematics of the onocleoid ferns. Univ. Calif. Publ. Bot. 61, 1-87.

Lloyd, R.M. (1976) Spore morphology of the Hawaiian genus Sadleria (Blechnaceae). Am. Fern J. 66, 17.

Ogura, Y. (1933) On the structure of a fossil stem of Cibotiumtype from the Upper Cretaceous of Iwate. Bot. Mag. (Tokyo), 47, 748-754.

Paris, C.A. (1991) Molecular systematics of the Adiantum pedatum complex: phylogeny, biogeography, and a taxonomic reconsideration of the group in North America. Ph.D. Thesis, University of Vermont.

Peck, J.H., Peck, C.J. \& Farrar, D.R. (1991) Influences of life history attributes on formation of local and distant fern populations. Am. Fem J. 81, 126-142.

Rotondo, G.M., Springer, V.G., Scott, G.A.J. \& Schlanger, S.O. (1981) Plate movement and island integration-a possible mechanism in the formation of endemic biotas, with special reference to the Hawaiian Islands. Syst. Zool. 30, 12-21.

Soltis, P.S. \& Soltis, D.E. (1990) Genetic variation within and among population of ferns. Am. Fern J. 80, 161-172.

Tryon, A.F. (1965) Origin of the fern flora of Tristan de Cunha. Brit. Fern Gaz. 9, 269-276.

Tryon, R.M. Jr (1949) Some woodsias from the north shore of Lake Superior. Am. Fern J. 38, 159-170.

Tryon, R.M. Jr (1970) Development and evolution of fern floras of oceanic islands. Biotropica, 2, 76-84.

Tryon, R.M. Jr (1971) The American tree ferns allied to Sphaeropteris horrida. Rhodora, 73, 1-18.

Tryon, R.M. Jr (1972) Endemic areas and geographic speciation in tropical American ferns. Biotropica, 4, 121-131.

Tryon, R.M. Jr (1986) The biogeography of species, with special reference to the ferns. Bot. Rev. 52, 117-156.

Tryon, R.M. Jr \& Stolze, R.G. (1989) Pteridophyta of Peru, Part II. 13. Pteridaceae-15. Dennstaedtiaceae. Fieldiana Botany N.S. 22.

Tryon, R.M. Jr \& Stolze, R.G. (1991) Pteridophyta of Peru, Part IV. 17. Dryopteridaceae. Fieldiana Botany N.S. 27.

Van der Hammen, T. (1981) The Pleistocene changes of vegetation and climate in the northern Andes, The glaciation of the Ecuadorian Andes (by S. Hastenrath), appendix iv, pp. 125145. A. A. Balkema, Rotterdam.

Wagner, W.H. Jr (1952) The fern genus Diellia-its structure, affinities, and taxonomy. Univ. Calif. Publ. Bot. 26, $1-212$.

Wagner, W.H. Jr (1972) Disjunctions in homosporous vascular plants. Ann. Mo. bot. Gdn, 59, 203-217.

Wagner, W.H. Jr (1990) Hawaii's Satchel-Sorus Tree Ferns, Cibotium species: what is their taxonomic status? Fiddlehead Forum, 17(1), 7-8.

Wolfe, J.A. (1975) Some aspects of the plant geography of the northern hemisphere during the late Cretaceous and Tertiary. Ann., Mo. bot. Gdn, 62, 264-279. 
. 